\title{
DESAIN ANIMASI INTERAKTIF DONOR DARAH MENGGUNAKAN ADOBE FLASH CS3 PROFESSIONAL
}

\author{
Abdul Hayat ${ }^{1}$ \\ Yuniar Putri Dian Sapitri ${ }^{2}$ \\ Renny Dwi Putri ${ }^{3}$
}

Email : ahayat@rekayasa.co.id ; yuniar@raharja.info; renny@yahoo.com

\begin{abstract}
ABSTRAK
Seiring berkembangnya teknologi informasi yang semakin hari semakin pesat dan seiring berkembangnya era modernisasi, hampir mencakup semua bidang dan semua aspek kehidupan yang takkan pernah luput dari yang nama teknologi dan trend, bahkan menjadi kebutuhan yang primer, salah satunya dunia pendidikan, dunia pendidikan yang kenal telah mengalami revolusi mengikuti perkembangan sesuai dengan perkembangan teknologi informasi yang sudah ada.

Semua hal bisa dibuat menjadi sebuah informasi, salah satunya Interaktif Donor Darah yaitu mengenal dan mengajak lebih dekat manfaat donor dan kegunaannya dalam kehidupan sehari hari serta menjadi lebih menarik dan semuanya termasuk di dalam interaktif donor darah itu merupakan hal yang wajib kita ketahui di era informasi yang menuntut kita mengikuti nya.

Sarana itu bisa diwujudkan dengan software adobe flash CS3 profesional. Software adobe flash CS3 profesional merupakan software multimedia yang mencakup semua unsur multimedia bahkan bisa digunakan menjadi programing dikemas dengan tidak membosankan dan menjadi teman belajar yang baik.
\end{abstract}

Kata Kunci: Animasi Interaktif, Donor Darah, Adobe Flash CS3 Profesional

\begin{abstract}
\footnotetext{
${ }^{1}$ Dosen Sistem Informasi STMIK Raharja Informatika

JI. Jend.Sudirman No. 40 Modern Cikokol-Tangerang 15117

${ }^{2}$ Dosen Sistem Komputer STMIK Raharja Informatika Jl. Jend.Sudirman No. 40 Modern Cikokol-Tangerang 15117

${ }^{3}$ Mahasiswa AMIK Bina Sarana Informatika Cabang Bumi Serpong Damai
}

As the development of information technology is increasingly rapidly as the development and modernization era, covering virtually all areas and all aspects of life that will never escape from the name of the technology and trend, and even become a primary requirement, one of the world of education, the education world has known been revolutionized following the development in accordance with the development of information technology that already exists. All things can be made into an information, one of which is Blood Donor Interactive knows and invites closer donor benefits and usefulness in their daily lives and become more attractive and interactive everything is 
included in the donor's blood is mandatory in the information age we know that requires us to follow him.

Means that can be realized by software adobe flash professional CS3. Adobe Flash CS3 Professional software is a multimedia software that includes all the multimedia elements can even be used to programing is packed with no boring and became a good friend to learn.

Keywords: Interactive Animation, Blood Donor, Adobe Flash CS3 Professional

\section{PENDAHULUAN}

Seiring dengan berkembangnya teknologi informasi yang semakin pesat yang hampir mencakup semua bidang dan semua aspek kehidupan yang tak akan pernah luput dari yang namanya teknologi dan trend, bahkan menjadi kebutuhan yang primer, salah satunya dunia pengetahuan. Dunia pengetahuan yang dikenal telah mengalami revolusi mengikuti perkembangan sesuai dengan perkembangan teknologi informasi yang sudah ada. Salah satu contoh penerapan dalam pengetahuan adalah edukasi dengan dikemas dengan animasi interaktif, dan merubah sistem pembelajarannya menjadi lebih menarik dan tidak monoton, edukasi dengan animasi interaksi ini mengoptimalisasikan konsep multimedia, dari audio visual yang berisi gambar dan yang menjadikan pembelajaran atau edukasi lebih menarik dan interaktif. Semua hal bisa dibuat menjadi sebuah edukasi melalui suatu informasi, salah satunya Interaktif Donor Darah yaitu mengenal dan mengajak lebih dekat manfaat donor dan kegunaannya dalam kehidupan sehari hari serta menjadi lebih menarik dan semuanya termasuk di dalam interaktif donor darah itu merupakan hal yang wajib kita ketahui di era informasi yang menuntut kita mengikuti nya. Sarana itu bisa diwujudkan dengan menggunakan software adobe flash CS3 profesional. Software adobe flash CS3 merupakan program multimedia yang mencakup semua unsur multimedia bahkan bisa digunakan menjadi programing dikemas dengan tidak membosankan dan menjadi teman belajar yang baik.

\section{TUJUAN DAN MANFAAT}

Tujuan dari pembuatan animasi interaktif ini untuk mengembangkan dan menginformasikan cara donor darah agar semua kalangan masyarakat sadar bahwa donor darah sangat bermanfaat bagi sesamanya, bahkan menguntungkan juga bagi para pendonornya dengan manfaat yang didapatnya. Selain itu merubah pola pikir yang tadinya donor darah seperti tidak penting menjadi sangat penting bagi semua kalangan.

\section{STUDI PUSTAKA}

\section{Animasi}

Menurut Fernandes (2002:1) mengemukakan bahwa "Animation is the process of recording and playing back a sequence of stills to achieve the illusion of continues motion", yang artinya "Animasi adalah sebuah proses merekam dan memainkan kembali serangkaian gambar statis untuk mendapatkan sebuah ilusi pergerakan". Berdasarkan arti harfiah, Animasi adalah menghidupkan yaitu usaha untuk menggerakkan sesuatu yang tidak bisa bergerak sendiri.

Secara garis besar, animasi komputer dibagi menjadi dua kategori, yaitu: 
a. Computer Assisted Animation, animasi pada kategori ini biasanya menunjuk pada sistem animasi 2 dimensi, yaitu mengkomputerisasi proses animasi tradisional yang menggunakan gambaran tangan. Komputer digunakan untuk pewarnaan, penerapan virtual kamera dan penataan data yang digunakan dalam sebuah animasi.

b. Computer Generated Animation, pada kategori ini biasanya digunakan untuk animasi 3 dimensi dengan program 3D seperti 3D Studio Max, Maya, Autocad dan lain sebagainya.

Menurut Zeembry (2006:1) animasi adalah rangkaian gambar yang disusun secara berurutan. Ketika rangkaian gambar tersebut ditampilkan dengan kecepatan yang memadai, rangkaian gambar tersebut akan terlihat bergerak. Secara garis besar, animasi komputer dibagi menjadi dua kategori, yaitu:

1. Computer Assisted Animation, animasi pada kategori ini biasanya menunjuk pada sistem animasi 2 dimensi, yaitu mengkomputerisasi proses animasi tradisional yang menggunakan gambaran tangan. Komputer digunakan untuk pewarnaan, penerapan virtual kamera dan penataan data yang digunakan dalam sebuah animasi.

2. Computer Generated Animation, pada kategori ini biasanya digunakan untuk animasi 3 dimensi dengan program 3D seperti 3D Studio Max, Maya, Autocad dan lain sebagainya.

\section{Animasi Interaktif}

Menurut Seels dan Glasgow dalam Arsyad (2004: 36) mengemukakan bahwa media interaktif merupakan sistem media penyampaian yang menyajikan materi video rekaman dengan pengendalian komputer kepada penonton (mahasiswa) yang tidak hanya mendengar dan melihat video dan suara, tetapi juga memberikan respon yang aktif dan respon itu yang menentukan kecepatan dan sekuensi penyajian. Media interaktif memiliki unsur audio-visual (termasuk animasi) dan disebut interaktif karena media ini dirancang dengan melibatkan respon pemakai secara aktif. Selain itu menurut Kamus Besar Bahasa Indonesia (KBBI), pengertian kata interaktif adalah "bersifat saling melakukan aksi; antar-hubungan; saling aktif." Kemudian arti lain ialah berkaitan dengan dialog antara komputer dan terminal atau antara komputer dan komputer.

Dari definisi diatas dapat diambil kesimpulan bahwa media interaktif adalah alat perantara yang dirancang dengan pemanfaatan komputer menggunakan unsur seperti suara (audio), gambar (visual) dan teks untuk menyampaikan suatu pesan. Sedangkan animasi interaktif berarti kumpulan gambar, garis, teks, atau unsur pembentuk objek lain yang memberikan efek gerakan (visual animasi) dan suara (audio) sehingga dengan efek tersebut pengguna dapat menerima pesan-pesan yang disampaikan dan dapat melakukan timbal balik terhadap animasi tersebut.

\section{Adobe Flash CS3 Professional}

Adobe Flash CS3 Professional menurut ( Andi, 2011:1 ) merupakan sebuah software yang dirancang untuk membuat animasi berbasis vector dengan hasil yang mempunyai ukuran kecil. Pada awalnya software ini memang diarahkan untuk membuat animasi atau aplikasi berbasis internet (online). Akan tetapi pada perkembangannya banyak di gunakan untuk membuat animasi atau aplikasi yang berbasis bukan internet (offline). 


\section{PEMBAHASAN}

\section{Perancangan Animasi Interkatif}

Penulis membuat sebuah perancangan animasi interkatif, yang mana perancangan tersebut adalah menggambarkan penggunaaan animasi interaktif dalam pembuatan animasi donor darah yang di recanakan untuk di tampilkan. Adapun rancangan tampilan-tampilan yang akan dibuat adalah:

1. Rancangan Tampilan Animasi Judul Pertama yang akan muncul adalah judul animasi dengan tulisan menggunakan Drop shadow yang bergerak secara otomatis,dapat dilihat pada gambar 1 .

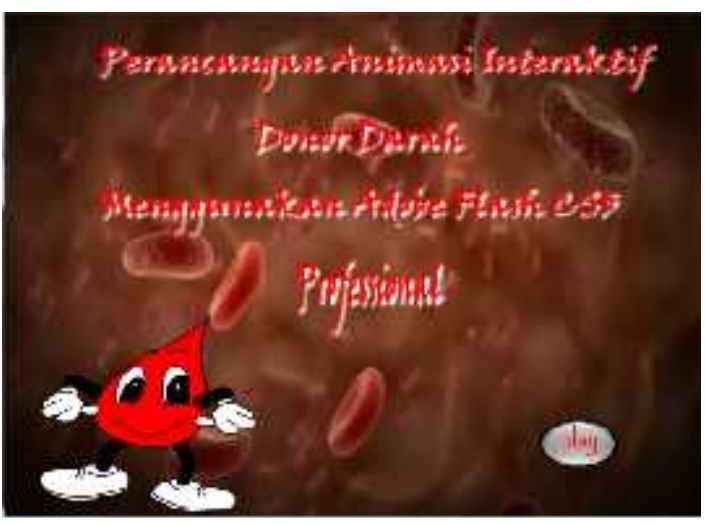

Gambar 1. Rancangan Tampilan Animasi Judul

2. Rancangan Tampilan Latar Belakang Latar belakang berisi sekilas tentang donor darah atau transfusi.tekan tombol next,yang bila dklik akan tampil tulisan next nya,dapat dilihat pada gambar 2 .

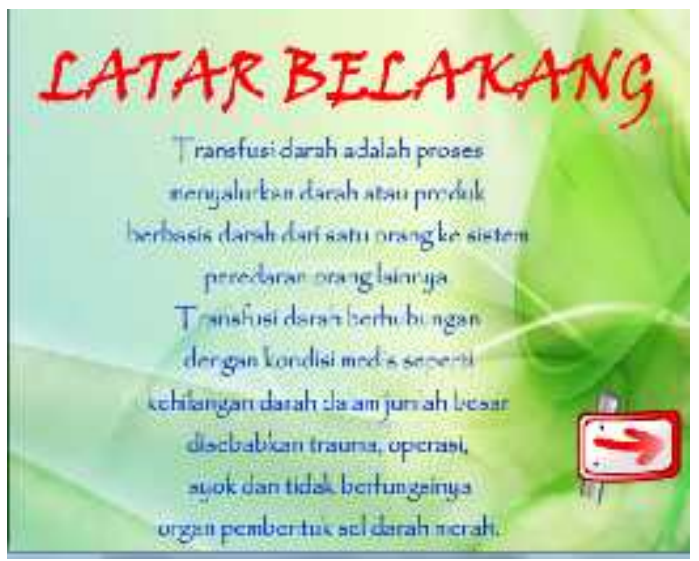

Gambar 2. Rancangan Tampilan

Animasi Latar Belakang

1. Rancangan Tampilan Animasi Menu Utama

Menu Utama ini adalah menu yang paling central atau yang paling penting dalam informasi donor darah ini, bila disentuh menu nya akan tampil tulisan menu,disini terdapat 5 pilihan menu yaitu: Persyaratan donor darah, Ciri khas tipe darah, Langkah-langkah donor darah ,Manfaat donor darah dan Tentang Saya,dapat dilihat pada gambar 3 .

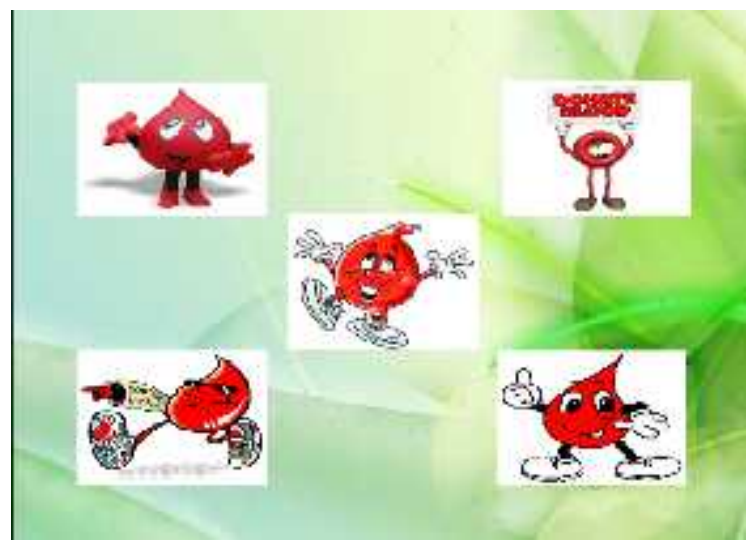

Gambar 3. Rancangan Tampilan Animasi Menu Utama

a. Persyaratan Donor Darah

Persyaratan ini menginformasikan tentang syarat-syarat atau ketentuan bagi pendonor yang akan mendonor kan darahnya,lihat pada gambar 4 . 


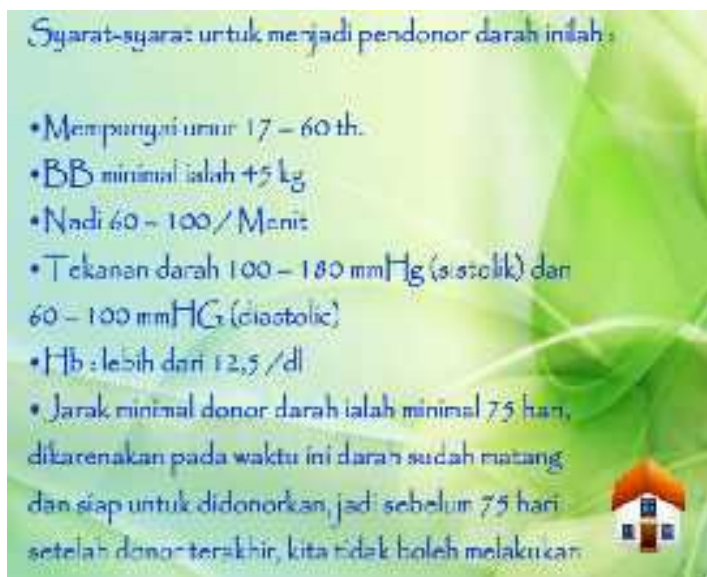

Gambar 4.Tampilan Syarat Donor Darah

b. Ciri Khas Tipe Darah

Menu Ciri Khas tipe darah ini berfungsi sebagai informasi mengetahui golongan atau tipe darah,bila d sentuh maka akan tampil tulisan menu nya,dapat dilihat pada gambar 5 .

\section{Ciri Khas tipe darah}
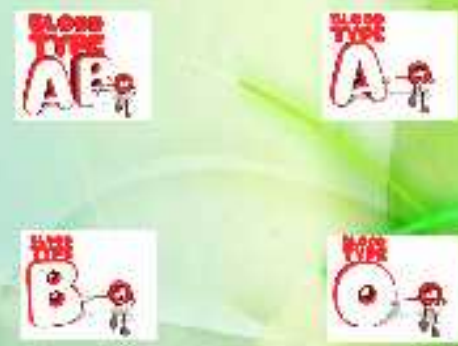

Gambar 5.Tampilan Menu Ciri Khas Tipe Darah

c. Langkah-langkah Donor Darah

Disini menginformasikan langkah pertama donor darah sampai terakhir pelaksanaan donor darah,serta tata cara tranfusi darah,lihat pada gambar 6 .

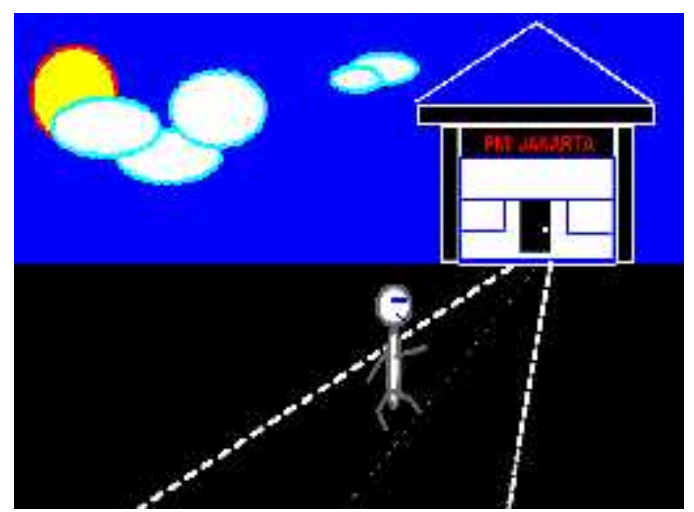

Gambar 6.Tampilan Langkah-langkah Donor Darah

Setelah datang di PMI maka kita akan mengisi formulir yang telah disediakan,lihat pada gambar 7 .

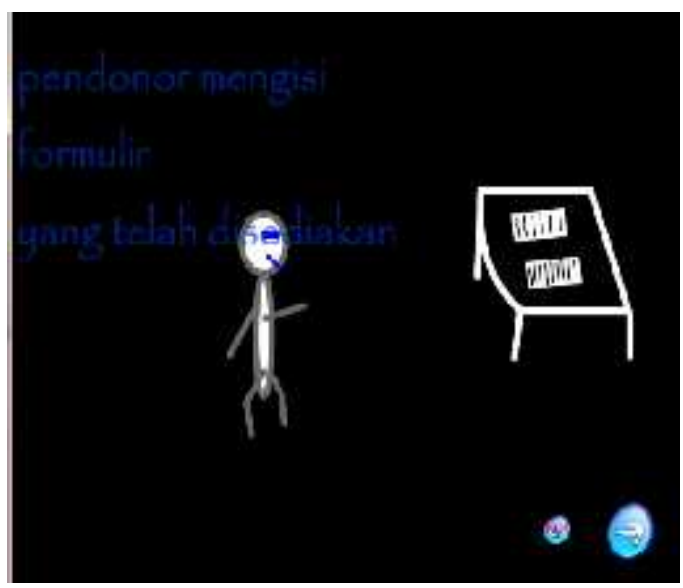

Gambar 7.Tampilan formulir

Formulir telah di isi selanjutnya mengecek kadar hemoglobinnya,dapat dilihat pada gambar 8 . 


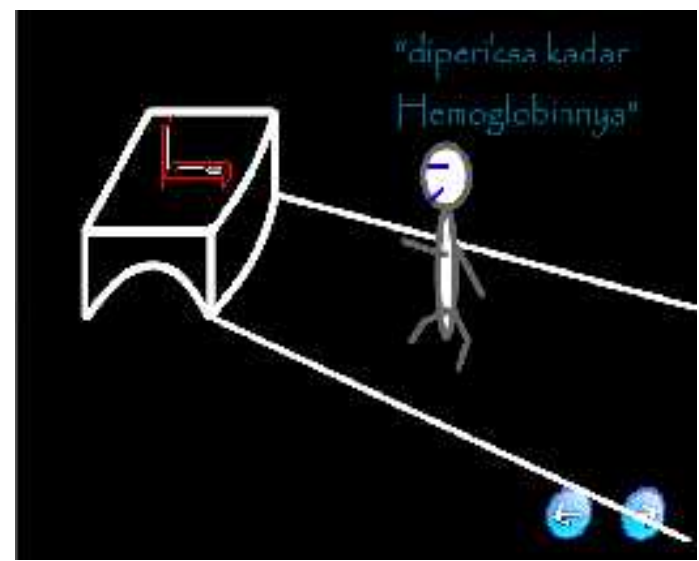

Gambar 8.Tampilan Cek hemoglobin

Setelah di cek kadar hemoglobinnya selanjutnya mencatat hasil pemeriksaan,dapat dilihat pada gambar 9 .

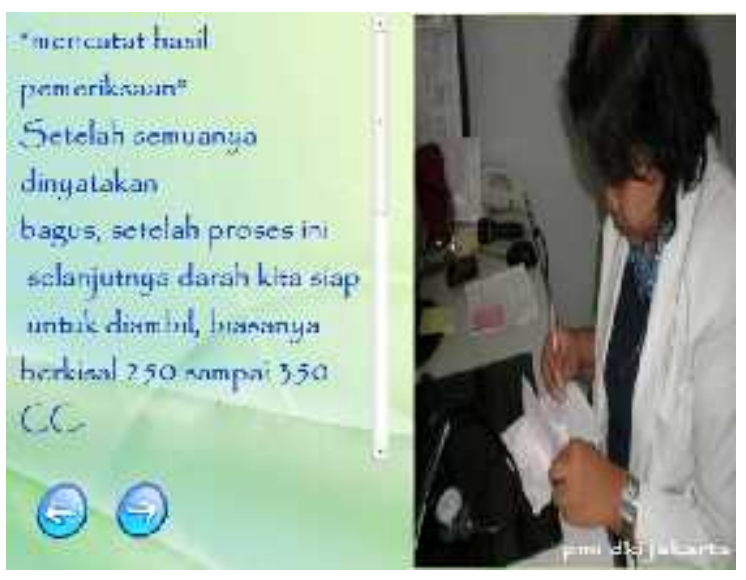

Gambar 9.Tampilan Hasil Pemeriksaan

Setelah semuanya dinyatakan bagus selanjutnya darah kita siap unutk diambil,dapat dilihat pada gambar 10 .

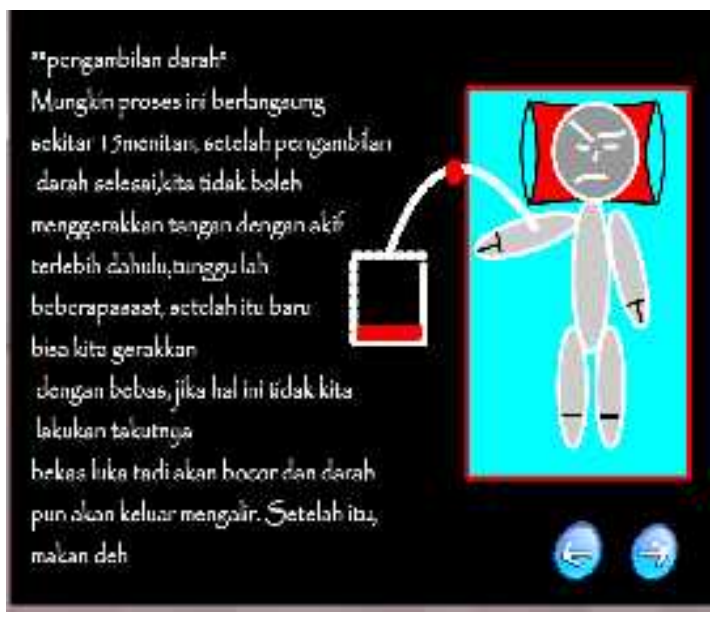

Gambar 10.Tampilan Pengambilan Darah

Setelah Pengambilan Darah,terakhir dilanjutkan dengan makan,yang telah disediakan,dapat dilihat pada gambar 11 .

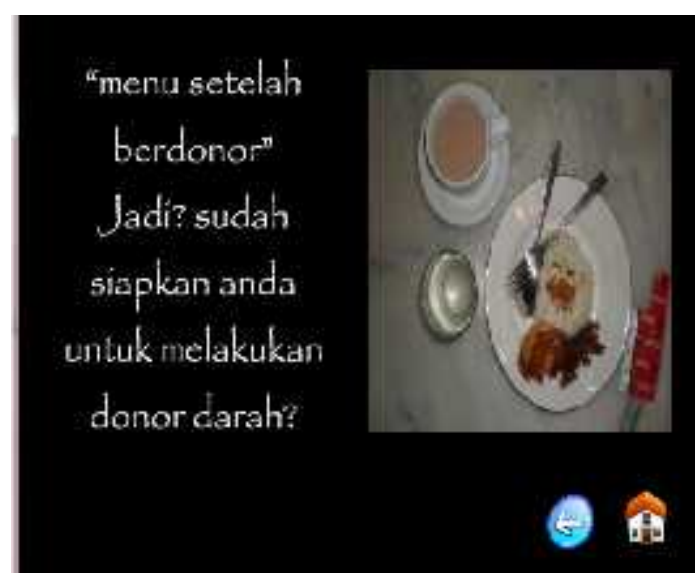

Gambar 11.Tampilan Menu setelah Donor

d. Manfaat Donor Darah

Di menu ini kita akan mengetahui manfaat melakukan donor darah serta mendapatkan informasi kegunaannya,dapat dilihat pada gambar 12. 


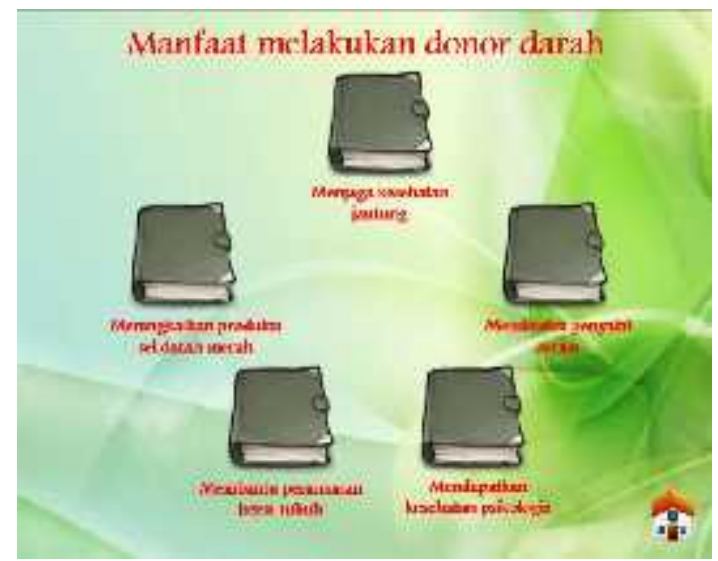

Gambar 12.Tampilan Menu Manfaat Donor Darah

\section{DAFTAR PUSTAKA}

1. Andi. 2009. Animasi Cantik dengan Adobe Flash. Yogyakarta : ANDI OFFSET.

2. Arsyad, Azhar. 2004. Media Pembelajaran. Jakarta: PT Raja Grafindo Persada.

3. Fernandes,Ibis.2002.1.Macromedia Flash Animation \& Cartooning London :A Creative Guide.

4. Zeembry.2006."123 Tip dan Trip Action

5. Script Flash MX 2004".Jakarta : PT.Elexmedia Komputindo

\section{KESIMPULAN}

Berdasarkan pembahasan mengenai pembuatan animasi interaktif diatas, secara umum kesimpulan penulis mengenai animasi tersebut akan dijelaskan sebagai berikut:

1. Adobe Flash CS3 telah mendukung penggunaan multimedia dalam berbagai jenis multimedia gambar,video,music,desain,dan game yang merupakan salah satu teknologi untuk mempermudah pembuatan animasi secara lebih mudah. Dengan keadaan yang demikian maka sangat memudahkan seseorang untuk menjadi seorang web design,programmer dan animator.

2. Sistem multimedia yang support terhadap hampir semua jenis file multimedia karna bisa mengunakan sistem import dan export file.

3. Pembuatan animasi interaktif ini sangat membantu untuk mendapatkan informasi secara menarik dan tidak membosankan karna disajikan dengan kemasan yang interaktif sehingga informasi pengetahuan akan lebih tampil secara menarik. 